\title{
Diálogo interreligioso y reconocimiento a la luz del legado de la ilustración
}

\author{
Interreligious dialogue and recognition in the light of the legacy of the \\ Enlightenment
}

\begin{abstract}
Emiliano Acosta*
Resumen

El presente artículo ofrece una concepción del diálogo interreligioso a partir del legado imaginario y conceptual de la llustración europea en sentido amplio. En primer lugar, se describe brevemente nuestro presente postsecular en cuanto espacio en el que se da el debate en torno al diálogo interreligioso. Esta descripción busca brindar una justificación para la presente investigación. En segundo lugar, se analiza la parábola de los tres anillos en Natán el sabio de Gotthold Ephraim Lessing. Se intenta mostrar: i) en qué medida la ilustración puede brindar imágenes (alegorías, metáforas) que sirvan a repensar el diálogo entre religiones; y ii) en qué medida el discurso de Lessing está condicionado por una lógica de la identidad, la cual impide un reconocimiento positivo de la particularidad de cada una de las religiones involucradas en el diálogo. En tercer lugar, se brinda una alternativa a este problema mediante el análisis de las concepciones del reconocimiento en dos autores de la ilustración alemana tardía, Schiller y Schelling. Ambos, se argumenta, conciben el reconocimiento desde una lógica de la diferencia, la cual hace posible una recuperación positiva del contenido particular de las religiones, mostrando que el diálogo sólo es posible a partir del reconocimiento de la dignidad de las diferencias de quienes participan en el diálogo. En cuarto lugar, por último, se ofrecen, a modo de conclusión, una serie de reflexiones con vistas a delinear una praxis de diálogo interreligioso a partir de la afirmación de la propia identidad y el reconocimiento del otro en su otredad.
\end{abstract}

Palabras clave: diálogo interreligioso - imagen - Lessing - Schiller - Schelling - reconocimiento

\begin{abstract}
Departing from a study of the imagery and conceptual legacy of European Enlightenment in broader sense, this article offers a conception of interreligious dialogue based on a logic of difference. First, our post-secular time is briefly described in order to justify the need of the present study. Secondly, Gotthold Ephraim Lessing's parable of the three rings in his Nathan the wise is analyzed in order to show, on the one hand, to what extent the Enlightenment can provide images (allegories, metaphors) for rethinking dialogue among religions, and, on the other, to what extent Lessing's account is conditioned by a logic of identity, which prevents a positive recognition of the particularity of each of the religions involved in the dialogue. Thirdly, an alternative to this problem is developed by examining the concepts of recognition in two authors of the late German Enlightenment, namely, Schiller and Schelling. Both, it is argued, conceive recognition from a logic of difference that results in a positive recovery of the particular content of religions. So, it is shown that dialogue is only possible if the dignity of the differences of the actors involved in the dialogue is recognized as such. Fourthly and finally, the article concludes with some reflections for outlining a praxis of interreligious dialogue based on both the affirmation of the own identity and the recognition of the other in his or her otherness.
\end{abstract}

Keywords: interreligious dialogue - imagery - Lessing - Schiller - Schelling - recognition

Artículo recibido el 02 de diciembre de 2016 y aprobado el 12 de junio de 2017.

* Professor of philosophy at the Vrije Universiteit Brussel and guest professor at Ghent University. He is member of the Young Academy of Belgium (Flanders), coordinator of the Latin-American Fichte Society (ALEF) and of the political philosophy network "Re-Thinking Europe". País de Origem: Bélgica. E-mail: emiliano.acosta@ugent.be

Horizonte, Belo Horizonte, v. 15, n. 46, p. 615-637, abr./jun. 2017 - ISSN 2175-5841 


\section{Introducción}

En lo que sigue, examinamos el concepto de diálogo interreligioso a partir de una lógica de la diferencia basada en el legado figurativo y conceptual de la Ilustración europea en sentido amplio (1650-1800). En la primera sección del presente artículo (1) ofrecemos una breve descripción de nuestro presente postsecular en cuanto espacio en el que se da el debate en torno al diálogo interreligioso. A partir de la misma intentamos brindar una justificación de la presente investigación.

La segunda sección (2) está dedicada al análisis de la parábola de los tres anillos en Natán el sabio de Gotthold Ephraim Lessing, una de las figuras centrales de la Ilustración alemana. Este análisis intenta mostrar en qué medida la Ilustración puede brindar imágenes (alegorías, metáforas) que sirvan a una comprensión del diálogo entre religiones y a una reconsideración del proyecto contemporáneo de un diálogo inter-religioso. Con esto buscamos, por un lado, problematizar las limitaciones conceptuales, históricas e ideológicas del discurso emancipador de la Ilustración, y, por otro, identificar aquellos conceptos y estrategias que pueden servir para repensar en nuestro presente la problemática inter-religiosa. Luego de indicar en qué medida la parábola de Lessing puede contribuir a un mayor esclarecimiento de la estructura del diálogo inter-religioso, argumentamos que la dificultad en el llamado a la tolerancia religiosa de Lessing consiste en que esta praxis de tolerancia está basada en una lógica de la identidad que tiene como efecto principal la negación de la particularidad de cada religión, es decir, la negación de la otredad del otro en cuanto aquello que hace del otro una singularidad irrepetible imposible de ser reducida a un mero ejemplo de un concepto o idea universal.

En la tercera sección (3) ofrecemos una reconstrucción de dos alternativas de la Ilustración tardía alemana al reconocimiento según una lógica de la identidad: el reconocimiento estético de Schiller y el reconocimiento en el disenso 
de Schelling. Para esto nos concentraremos en dos obras escritas en el periodo inmediatamente posterior a la Revolución Francesa, Cartas para la educación estética del hombre de Friedrich Schiller (1795) y la Nueva deducción del derecho natural de Friedrich Wilhelm Joseph (von) Schelling (1796/97).

Ambas alternativas al concepto habitual de reconocimiento servirán para delinear, a modo de conclusión (4), una praxis de diálogo interreligioso que no necesite sostenerse en el concepto moderno o iluminista de tolerancia entre religiones en cuanto indiferencia mutua, sino que tenga como punto de partida la idea de que todo diálogo productivo y enriquecedor debe comenzar y estar basado en un disenso fundamental en cuanto espacio que no sólo haga posible, sino que además torne necesaria, la apertura hacia el otro en su singularidad irrepetible a partir tanto de la afirmación de la propia identidad como del reconocimiento del otro en su otredad constitutiva.

\section{Presente post-secularizado, diálogo interreligioso e Ilustración}

Sin duda alguna la así llamada muerte de Dios significó no sólo un debilitamiento de la religión ${ }^{1}$-tanto en cuanto institución como en cuanto experiencia individual de transcendencia- y de la teología, sino también de la Ilustración. Estos discursos aparecen, en efecto, como el blanco perfecto de la crítica que en los dos últimos siglos se llevó a cabo contra toda ideología alienante (Marx), contra toda forma de universalismo y/o totalitarismo (Horkheimer \& Adorno), contra todo discurso que se pretende portador de la Verdad (Foucault) y contra todo gran relato (Lyotard). Sin embargo, a pesar de la dureza y fuerza persuasiva de esta crítica nuestro presente globalizado o, para decirlo con Habermas, nuestra "sociedad post-secular" (2001, p. 13), muestra indicios

\footnotetext{
${ }^{1}$ Es necesario aclarar aquí que este debilitamiento no debe interpretarse exclusivamente en sentido negativo. Tal como Vattimo ha mostrado, el debilitamiento de la religión, que él también llama "secularización positiva", ha significado en el caso de la Iglesia Católica Apostólica Romana el debilitamiento de la prepotencia y violencia de la Iglesia y, en consecuencia, debe entenderse positivamente como un proceso histórico que abre la posibilidad a una Iglesia de la caridad y de la paz (VATTIMO, 1997, p. 36).
} 
suficientes de haber abandonado el horizonte de sentido al que refiere el conocido dictum nietzscheano. ${ }^{2}$

En efecto, los tiempos de la crisis tanto del discurso de la Ilustración como de toda referencia hacia una transcendencia parecen haber dejado lugar a un nuevo ámbito donde se torna posible una recuperación tanto teórica como práctica de la religión (PAIVA, 2015, p. 407-8 y 416-7), de la teología (VANHOOLZER, 2003, p. 5) y del pensamiento secularizador y secularizado de la Ilustración (ISRAEL, 2006). Nuestro presente es testigo entonces del revival, por un lado, de la religión, la fe y la espiritualidad, incluso en círculos extraños a las religiones como en el caso de la "espiritualidad atea" (HOUTMAN \& AUPERS, 2007), y, por otro, de pilares conceptuales de la Ilustración tales como las ideas de cosmopolitismo y equidad (BEITZ, 2005). Resulta, por cierto, interesante advertir que religión, teología e Ilustración, estos enemigos íntimos de antaño, se encuentran hoy de algún modo unidos en su lucha por recuperar el espacio perdido en la esfera pública moderna y postmoderna. 3

Ahora bien, el hecho de que la religión, la teología y la Ilustración se hallen unidas en cuanto objetos de la crítica moderna y posmoderna no implica necesariamente la posibilidad de una cooperación entre estos discursos. En lo que concierne al tema del presente artículo, una reconsideración del debate actual sobre diálogo interreligioso desde una perspectiva forjada a partir del legado de la Ilustración parece a primera vista algo imposible o contradictorio en sí mismo. $\mathrm{Si}$ bien es cierto que en los últimos años se ha intentado mostrar la cercanía

\footnotetext{
${ }^{2}$ Precisamente en esto radica el carácter post-secular de nuestra época, a saber: en que todo discurso con pretensiones de validez universal (sea una religión, una teoría metafísica, una ideología) ya no despierta adhesión, sino rechazo. Un rechazo que en primer lugar no tiene otra razón más que la desconfianza ante todo gesto universalista a raíz de su identificación con el totalitarismo en el pensar, hacer y decir. Es esta actitud post-secular, por cierto, la que permite pensar el diálogo interreligioso como posible. Es esta misma actitud la que se halla presente en el concepto de secularización positiva de Vattimo (véase nota 1).

3 "Moderno" y "postmoderno" son sin duda términos polisémicos que siempre deben ser aclarados a la hora de utilizarlos. En el contexto del presente artículo deben entenderse ambos términos en su significación más básica, a saber, en cuanto indicadores de dos momentos de la historia de la cultura y del pensamiento occidentales. "Moderno" refiere al período iniciado por las revoluciones en la ciencia, la filosofía y la religión representadas, entre otros, en el pensamiento de Galileo, Descartes y Lutero, y que finaliza con la crisis cultural que tiene, entre otras manifestaciones o síntomas, Auschwitz. Lo "posmoderno" se identifica no en primer lugar con la así llamada filosofía posmoderna, sino con el periodo que se inicia luego de la primera mitad del siglo XX y comienza a cristalizarse en la filosofía con el estructuralismo. El punto principal de diferencia con lo moderno reside en la negación y denuncia (moral, política) de todo universalismo en cuanto pensamiento totalitario. En este sentido, y sólo en este sentido, nuestro presente anti-universalista y pluralista puede seguir siendo considerado postmoderno.
} 
conceptual entre la Ilustración (o la ilustración radical) y las concepciones actuales de democracia, tolerancia, inclusión y diálogo -para de este modo desacreditar el ataque posmoderno contra la Ilustración- (ISRAEL, 2006, pp. 3-11 y 807), debemos empero reconocer que al discurso de la Ilustración, tanto en su versión conservadora como en su versión progresista o radical, le es inherente una pretensión de universalidad y Verdad ajenas, o incluso contrarias, a los estándares del pluralismo de nuestros días. A esto debe añadirse que en el caso particular de la problemática actual acerca del diálogo interreligioso la Ilustración no parece ofrecer ninguna otra solución más que la tolerancia política de las distintas religiones a partir de la negación o indiferencia de la particularidad de cada religión (DESCOULEURS, 2005).

Distintos acontecimientos de los últimos años -como, por ejemplo, la sanción de la ley sobre uso de signos religiosos en establecimientos escolares públicos franceses en 2004- permiten ver que la supuesta solución laicista de la Ilustración no sólo no ha sido efectiva, sino que además se ha transformado en un generador de nuevos conflictos tanto entre las religiones como entre algunas religiones, el poder político y la opinión pública (BALIBAR, 2004). La fórmula de la Ilustración en la que se basa esta solución laicista, a saber: tolerancia de las distintas religiones mediante la subordinación de las mismas a una verdad no religiosa, es decir, mera tolerancia sin intento alguno por comprender cada una de las religiones en su particularidad, es precisamente el polo opuesto de lo que se quiere expresar en nuestros días con el concepto de lo inter-religioso.

En efecto, para entender lo particular del diálogo interreligioso se debe prestar atención, como sugieren varios autores, a lo que se quiere decir con el uso del prefijo 'inter' en 'interreligioso'. 'Inter' no significa meramente encuentro de religiones, sino que implica apertura y avidez para comunicarse con gente de otras creencias, para aprender del otro (STROUSE, 2016, p. 110), para construir junto con el otro un nuevo marco de referencia para una intersubjetividad que incluya las más distintas expresiones religiosas sin, por esto, debilitar o relativizar la 
pretensión de verdad de cada religión (ORTEZA y MIRANDA, 2010). Se trata de lograr "la comprensión mutua y la cooperación para encontrar las raíces epistemológicas y metodológicas del juicio de valor y de conceptos tales como libertad [y] justicia” (HACINEBIOGLU, 2010, p. 82). En el diálogo interreligioso el otro ya no aparece como un extraño, sino que es redescubierto como "prójimo" (LIGHT, 2009).

Tal vez el punto en el que el discurso de la Ilustración sobre tolerancia y libertad religiosas se separa completamente del concepto de diálogo interreligioso sea la convicción de este último de que la tensión entre comprensión mutua y afirmación de la propia identidad en modo alguno debe ser anulada. Así, por ejemplo, uno de los principales impulsores del diálogo interreligioso, a saber, la iglesia Católica Apostólica Romana4, sostiene que:

[d]esde el principio era claro que dicho diálogo [sc. diálogo interreligioso] no implicaba relativizar la fe cristiana, o dejar a un lado el anhelo, que anida en el corazón de todo discípulo, de anunciar a todos la alegría del encuentro con Cristo y su llamada universal. Por lo demás, el diálogo sólo es posible a partir de la propia identidad. (FRANCISCO, 2014)

Ahora bien, teniendo en cuenta lo expuesto: ¿cómo justificar la necesidad de recurrir a la Ilustración para repensar el diálogo interreligioso? Si bien la Ilustración no brinda un concepto de lo interreligioso en sentido estricto, creemos que los tres autores que nos proponemos analizar, Lessing, Schiller y Schelling, proveen imágenes, conceptos y estrategias metodológicas que pueden servir a esta tarea de repensar el horizonte teórico y práctico del diálogo interreligioso.

La parábola de los tres anillos de Lessing, es cierto, defiende una idea de tolerancia entre religiones que no implica el diálogo inter-religioso. La estrategia de Lessing, en consonancia con el pensamiento de la Ilustración en general sobre

\footnotetext{
${ }^{4}$ Ciertamente puede aquí objetarse que ésta sea la posición de la Iglesia Católica Apostólica Romana en su totalidad. Existen sectores dentro de esta institución que en modo alguno están de acuerdo con la idea de una apertura hacia el diálogo interreligioso. Ahora bien, la voz oficial de una institución es siempre la voz del sector que en ese momento se halla en el poder de la misma. Aceptando que la posición de Francisco no se identifica inmediatamente con la visión de todos los grupos organizados que componen la iglesia, es decir la ICAR en cuanto diversidad, debemos de todos modos reconocer que en este momento la voz del sector con el que el Papa se identifica encarna la voz oficial de la ICAR en cuanto institución.
} 
las religiones, consiste en demostrar que todas las religiones deben ser toleradas dentro de un Estado, puesto que todas, si bien de un modo imperfecto, están basadas en la religión que es natural a todo hombre en cuanto ser racional. En este contexto, tolerar no significa pues nada más que dejar hacer, siempre y cuando el creyente reconozca que por encima de su verdad se halla la verdad de la razón. Sin embargo, la parábola de Lessing puede contribuir al desafío actual del diálogo inter-religioso en la medida en que nos ofrece un conjunto de conceptos que permiten comprender mejor en qué consiste un diálogo entre personas de distintas religiones. En su Natán el sabio Lessing logra mostrar que todo diálogo comienza necesariamente con el desconocimiento del otro (ignorancia, juicio equivocado sobre el otro, demonización del otro), que todo diálogo parte de una situación de asimetría entre los actores involucrados y que el diálogo fructífero es aquel que logra cambiar a las personas o, dicho más precisamente, que logra hacer de las personas mejores seres humanos.

En el caso de Schiller y Schelling, bien puede objetarse que la idea de ser humano y de humanidad que ambos defienden es, en cuanto moderna y más precisamente ilustrada, universalista. Sin embargo, como intentaremos mostrar, dentro de ese condicionamiento histórico y cultural ambos autores han podido pensar el reconocimiento en cuanto una praxis destinada a afirmar diferencias y no a neutralizarlas bajo una idea o ideal de humanidad concretos. El reconocimiento estético de Schiller, como mostraremos, no desconoce la verdad de la razón de la Ilustración, pero, al advertir su poder opresor de la individualidad humana, suspende momentáneamente su validez cuando se trata de concebir relaciones intersubjetivas que respeten la dignidad de cada individuo. La teoría de Schelling de un reconocimiento en el disenso tampoco desconoce la validez universal de la razón ni el hecho de que todo ser racional es manifestación de una misma razón, pero lleva el contenido del ideal de la razón a un nivel de indeterminación que permite que la intersubjetividad promueva y conserve la pluralidad de perspectivas y fuerzas de cada individuo racional. 
El recurso al legado de la Ilustración, entonces, ayuda a repensar nuestros problemas, sin por esto brindar una solución concreta mediante la aplicación directa de alguna concepción de la Ilustración en sentido estricto. Sucede aquí pues algo similar a lo que podemos ver en otros debates actuales en los que el legado de la Ilustración de algún modo participa. Por ejemplo, en lo que concierne al debate actual sobre democracia hemos mostrado en otro lado (ACOSTA, 2014a) que el concepto de Spinoza de democracia, si bien puede sonar totalitario a nuestros oídos post-seculares, 5 nos permite no sólo visualizar la estructura compleja y conflictiva de la democracia, sino además reconocer que el conflicto de intereses entre actores políticos y apolíticos (para Spinoza: los profetas; para nuestro presente: los medios de comunicación, el discurso de los expertos y el poder económico) es inherente a toda democracia. No es nuestra intención, por consiguiente, apelar a la Ilustración como instancia proveedora de definiciones verdaderas, sino como espejo en el que nuestro presente puede llegar a ver sus problemas, desafíos y horizontes de trabajo.

\section{Lessing: una parábola ilustrada para pensar lo religioso}

\subsection{El uso de la imagen para expresar una idea filosófica}

Natán el sabio ${ }^{6}$, poema dramático en cinco actos publicado en 1779 y escenificado por primera vez en 1783 en Berlín, es, como se sabe, la última obra que Lessing llegó a escribir. La historia del sabio Natán, de sus vicisitudes como judío en tiempos de la tercera cruzada (1187-1191) en una Jerusalén en manos sarracenas y del modo en que personas de distintos credos (cristianos, musulmanes y judíos) pueden relacionarse pacíficamente, sirve como el velo figurativo bajo el que Lessing presenta sus ideas de humanidad, humanismo y tolerancia.

Debe recordarse aquí que Lessing recurre en este caso al lenguaje poético para expresar sus ideas filosóficas y religiosas a raíz de la prohibición que pesaba

\footnotetext{
${ }^{5}$ Acerca del concepto de post-secular véase la nota 2.

${ }^{6}$ Citaremos en el cuerpo de texto con números romanos los actos y con números arábigos las escenas de esta obra.
} 
sobre él para publicar escritos sobre cuestiones religiosas. Esta censura, la cual puso fin al privilegio especial de libertad de expresión del que gozaba Lessing en cuanto director de la Biblioteca Augusta de Wolfenbütte (Herzog August Bibliothek), es el momento culminante de la así llamada Disputa de los fragmentos (Fragmentenstreit).

Lessing se vio envuelto en esta polémica a raíz de su decisión de publicar ciertos fragmentos de Hermann Samuel Reimarus en los que este catedrático en lenguas orientales defendía el deísmo, la religión natural o racional, y atacaba a las religiones fundadas tanto en escritos sagrados como en la revelación de Dios a los hombres en un momento específico de la historia de la humanidad. El pastor y teólogo luterano Johann Melchior Goeze fue quien dirigió la reacción, por cierto, exitosa, contra la osadía de Lessing de desacreditar la dignidad de las religiones.

En este sentido, no podemos esperar de Lessing, y en particular de su Natán el sabio, otra cosa más que la afirmación de su credo ilustrado, según el cual no existe la religión verdadera, sino que todas las religiones son versiones parciales de una única religión natural a todos los hombres. El recurso a la imaginería, una obra de teatro y dentro de la misma el recurso a una parábola, para expresar un punto de vista sobre tolerancia religiosa no es en el caso de Lessing pues un acto espontáneo o libre, sino antes bien una estrategia para sortear la censura.

\subsection{La parábola de los tres anillos}

En Natán el sabio Lessing relata cómo las tres principales figuras de esta obra, el judío Natán, el sultán musulmán Saladino y un templario cristiano, logran superar las diferencias y condicionamientos de sus respectivas religiones en una praxis de reconocimiento mutuo en cuanto seres humanos sin más. La humanidad y no las religiones es aquello que, según Lessing, une a estos tres personajes. Cada uno, actuando convencido de estar obedeciendo su propio credo, no está sino siguiendo la religión que es natural a todo hombre, la religión de la humanidad o, 
dicho en términos de la Ilustración, la religión de la razón universal. El ideario post-religioso de la Ilustración, la relativización de las nociones particulares de Dios, es lo que hace posible, según Lessing, el diálogo, la amistad y la tolerancia entre judaísmo, islamismo y cristianismo en una ciudad atravesada por el conflicto religioso en torno a Jerusalén.

La parábola de los tres anillos constituye el corazón de la obra. Todas las acciones han sido dispuestas por Lessing de modo tal que confluyan en la escena central en que esta parábola es puesta en boca de Natán (III, 7). Natán se vale de esta parábola para evitar responder a una pregunta tan engañosa como peligrosa que le ha hecho el sultán Saladino, a saber, cuál de las tres religiones monoteístas es la verdadera, pues "de estas tres", afirma Saladino, "sólo una puede ser verdadera" (III, 5).

Ahora bien, Saladino no ha ido al encuentro de Natán en busca de sabiduría, sino de dinero. Saladino debe pagar deudas e ingenia un plan para hacerse de los bienes de Natán, cuya riqueza era conocida en Jerusalén. Con su pregunta acerca de la religión verdadera Saladino quiere poner en aprietos a Natán. Pues supone que, si Natán dice su verdad, a saber, que el judaísmo es la verdadera religión, tendrá entonces la excusa perfecta para privar a Natán de su libertad y de sus bienes: Saladino podrá argumentar que Natán ha desconocido la dignidad de la religión del Sultán (III, 4). Así Saladino podrá 'tomar' un préstamo de Natán sin estar obligado en lo más mínimo a devolver la suma recibida. Como es sabido, Natán no responde del modo esperado por Saladino, sino con una parábola que muestra que ninguna de las tres religiones es la verdadera y, sin embargo, las tres son hijas del mismo Dios y, por consiguiente, hermanas. En el acto anterior a esta escena Lessing ya nos ha dado indicios de que la respuesta de Natán nunca sería una apología del judaísmo. Pues, como afirma Al-Hafi, otro de los personajes de esta obra, "judío y cristiano/ y musulmán y parsi, todo es para él [sc. Natán] lo mismo" (II, 2). 
La parábola de los tres anillos cuenta la historia de un anillo con el poder de transformar a quien lo posee en una buena persona, estimada tanto por Dios como por sus semejantes. Este anillo, relata Lessing por medio de Natán, ha ido pasando de generación en generación dentro de una misma familia, en la que cada padre ha entregado el anillo al más virtuoso y amado de sus hijos. Luego de varias generaciones se da entonces el caso de que el padre poseedor del anillo tiene tres hijos a quienes estima de igual manera, lo cual le impide decidir quién merece el anillo. Estando cercana su muerte, "la piadosa debilidad" de este padre, hace decir Lessing a Natán, "hizo que prometiera el anillo a cada uno de los tres" (III, 7). Para salir de este aprieto el padre encarga dos réplicas del anillo, de modo tal que cada hijo por separado reciba un anillo creyendo que se trata del anillo.

A diferencia de la versión de Boccaccio de la parábola del anillo, la cual constituye la tercera novela de la primera jornada del Decamerón (1982, pp. 3638), en la versión ilustrada de Lessing la historia prosigue. Una vez muerto el padre, los hijos, al darse cuenta del engaño, comienzan a rivalizar entre sí acerca de quién posee el verdadero anillo. La discusión es llevada a un juez quien en primer lugar constata que ninguno de los tres anillos es el verdadero, pues él no ve el efecto mágico del anillo en ninguno de los tres hermanos. Ninguno demuestra ser virtuoso, ninguno es apreciado por los demás, sino que cada uno se ama más a sí mismo que a su prójimo. A raíz de esto el juez, en segundo lugar, exhorta a los hermanos, una vez demostrado que el anillo se ha perdido para siempre, a vivir virtuosamente siguiendo las enseñanzas de su padre, de modo que el poder del anillo vuelva a manifestarse, si bien ya no más como un milagro, sino antes bien como el resultado del obrar virtuoso de cada uno de los hermanos.

Natán hace ver de este modo a Saladino que todas las religiones son tan verdaderas como falsas. Verdaderas son ellas en cuanto doctrinas de virtud y sabiduría, falsas son ellas en cuanto portadoras exclusivas de la Verdad. Las tres religiones que aún se creen auténticas dueñas de Jerusalén son según Lessing como hermanos. Con esta parábola, que Natán había propuesto a Saladino como mera 
introducción a su respuesta (III, 7), Natán convence a Saladino de la verdad de la Ilustración sobre las religiones. Saladino entonces se disculpa ante Natán y le ofrece su amistad. Natán, por su parte, acepta el ofrecimiento y le presta desinteresadamente el dinero que el sultán por medios poco virtuosos quería conseguir.

\subsection{Las condiciones del diálogo entre Natán y Saladino}

$\mathrm{Si}$, como hemos dicho anteriormente, el concepto mismo de tolerancia entre religiones que Lessing presenta en su Natán el sabio no ofrece una perspectiva productiva para repensar el diálogo interreligioso, cabe entonces preguntar: ¿qué nos puede enseñar Lessing?

Creemos que la parábola de Lessing resulta instructiva en nuestro presente precisamente en al menos cuatro aspectos de la parábola de Lessing que suelen ser ignorados, tal vez por ser considerados secundarios. Estos aspectos refieren a la situación misma en la que se da el diálogo y a la dinámica del mismo:

i) En primer lugar, el diálogo entre el sabio Natán y el sultán Saladino no es en modo alguno una situación deseada por ninguno de los dos: Saladino recurre a Natán obligado por sus problemas económicos (II, 2). Natán, por su parte, se ve forzado a aceptar el diálogo dadas las terribles consecuencias que una negativa a la invitación del sultán tendría para su propia existencia (III, 6).

ii) En segundo lugar, ni el sultán ni el sabio actúan en principio de un modo franco. Con su pregunta el sultán no desea saber en verdad cuál de las tres grandes religiones monoteístas es la verdadera, sino antes bien poner en aprietos a Natán, de modo que la apropiación de los bienes de Natán resulte justificada. El recurso a la parábola de los tres anillos es en principio para Natán un modo de evitar la verdadera pregunta. Natán no quiere decir su verdad, sino contestar de modo tal que quien pregunta se vea satisfecho con la 
respuesta (III, 6). La idea de responder a la pregunta del sultán por medio de la parábola es en principio para Natán una estrategia para evadir la pregunta.

iii) En tercer lugar, tanto Natán como Saladino parten de una idea falsa sobre el otro. Cada uno demoniza al otro definiéndolo con prejuicios y preconceptos. Para Saladino Natán no es una buena persona, sino, dado que es judío, el "más avaro" de todos los hombres (II, 2). Para Natán el Sultán no es digno de tal investidura, pues, entregado a sus placeres, abusa de su poder político y en lugar de velar por sus súbditos, busca vivir de ellos: "el mendigo verdadero”, dice Natán, “no es sino el verdadero rey” (II, 9).

iv) En cuarto y último lugar, al inicio del diálogo Natán y Saladino no se hallan en igualdad de condiciones. La relación es asimétrica: Saladino puede terminar la conversación en cualquier momento y hacer uso de su poder político. Natán es ante Saladino un súbdito, de allí que sus posibles movimientos sean desde un inicio acotados. El poder del Sultán es de verse en el hecho de que es él quien puede preguntar. Natán nunca imagina que él podría repreguntarle a Saladino cuál es la verdadera religión.

\subsection{Reconocimiento de acuerdo a una lógica de la identidad}

Ahora bien, a pesar de lo que acabamos de indicar el diálogo entre Natán y Saladino tiene como resultado el reconocimiento y respeto mutuo, lo cual se refleja en la amistad que ambos sellan al final de la parábola. Lessing parece decir que una praxis dialógica por medio de la cual se establecen relaciones de tolerancia y reconocimiento recíproco no debe comenzar necesariamente con un consenso básico entre las partes. Como en el caso de Natán el sabio muchas veces una amistad surge de un proceso iniciado tal vez con otros fines. El diálogo es el lugar en el que sucede el redescubrimiento del otro que pone en crisis los prejuicios que teníamos sobre el otro. Conocimiento y reconocimiento recíproco sucede solamente si uno se decide a interactuar, no importa con qué fines, con el otro. 
En la obra de Lessing, sin embargo, el tipo de reconocimiento que acontece, si bien garantiza la tolerancia religiosa, sigue una lógica de la identidad que, como se ha indicado al inicio con el ejemplo de la ley sobre el uso de símbolos religiosos en las escuelas francesas, hoy ya no es efectiva. La amistad que sellan Natán y Saladino está basada en el reconocimiento recíproco en cuanto seres humanos, miembros de la gran familia de la Humanidad, pero no en cuanto judío y musulmán. Sólo cuando Saladino da muestras de haber entendido el mensaje de Natán, éste puede reconocer que Saladino antes que musulmán es un ser humano. El ofrecimiento de amistad de Saladino no es el ofrecimiento que un musulmán hace a un judío, sino el ofrecimiento de un hombre sin más a otro hombre sin más. Por un lado, para ser reconocido como ser humano sin más, esto es, para ser digno de la amistad de Natán, Saladino debe dejar de ser musulmán. Por otro lado, para que Saladino ofrezca su amistad a Natán, Natán debe dejar de ser visto como aquel judío avaro, para pasar a ser nada más que un hombre, un hermano, un mero prójimo. La concordia entre ambos se da pues bajo el concepto universal de hombre. Judío, cristiano, musulmán no son sino accidentes que no afectan la substancia (el hombre en cuanto ser racional sin más).

El diálogo puede resolverlo todo, nos dice Lessing, pero la solución ofrecida parece negar el problema principal, es decir, las diferencias religiosas. Por un lado, el reconocimiento por medio del cual Saladino en cuanto mero ser humano es incluido en la gran familia de la Humanidad supone la exclusión de Saladino en cuanto musulmán. La inclusión pensada desde la identidad, entonces, excluye. Por otro lado, ces el diálogo de la parábola de los tres anillos un proceso en el que las partes aprenden algo del otro? Si bien Saladino aprende lo que es según Natán un obrar virtuoso con respecto a gente de otros credos, no se puede decir lo mismo de Natán. La amistad entre ambos ha sido posible porque Saladino se ha convertido al humanismo y a la religión natural tanto de Natán como de Lessing. Natán ya sabía todo. El diálogo sólo ha confirmado su credo iluminista. Por cierto, la demonización de Natán acerca de Saladino no ha sido resuelta, sino confirmada, pues Natán se hace amigo no del musulmán, sino del hombre en Saladino. Natán 
no busca en momento alguno saber qué es en verdad un musulmán. La misma estrategia de tolerancia y amistad puede verse en la escena en que Natán convence al templario cristiano:

iVen, tenemos que ser amigos! Puedes despreciar mi pueblo tanto como quieras. Ninguno de nosotros dos ha escogido su pueblo. ¿Somos acaso nosotros nuestro pueblo? ¿Pues qué significa pueblo? ¿Son cristianos y judíos primero cristianos y judíos antes que hombres? (II, 5)

Cabe preguntarnos aquí si no ha sido muy alto el precio que se ha pagado por la amistad, el reconocimiento y la tolerancia entre hombres de distintos credos. Pues, ¿qué es lo que se tolera, a los ojos de Natán y de Lessing, sino el error, la superstición o la ignorancia? ¿Respeta este tipo de inclusión y reconocimiento la dignidad del hombre, no en sentido de la Ilustración, por cierto, sino en el sentido de nuestras sociedades pluriculturales?

\section{Reconocimiento de acuerdo con las lógicas de la identidad y de la diferencia}

Para encontrar una salida a este dilema proponemos continuar nuestra investigación en el suelo de la Ilustración, si bien moviéndonos hacia los últimos años de este proceso: la tardía Ilustración alemana (1784-1800). Como mostraremos aquí dos exponentes de este período, Schiller y Schelling, pueden proveernos de una alternativa para pensar el reconocimiento, la tolerancia, el diálogo y la inclusión.

\subsection{Schiller y el reconocimiento estético del otro}

En sus Cartas sobre la educación estética del hombre Schiller ofrece una visión muy particular, dentro de su contexto filosófico y político, del reconocimiento.7 Según Schiller el verdadero desafío de la intersubjetividad no es

${ }^{7}$ Para un estudio detallado del concepto Schilleriano de reconocimiento véase ACOSTA, 2012. 
reconocer al otro como lo mismo que uno (como en el caso de Natán), sino reconocer al otro en sus diferencias y, a su vez, reconocer que estas diferencias son constitutivas de la identidad del otro, es decir, ellas no son lo accidental que debe ser dejado de lado para que la verdad del individuo, su humanidad en cuanto ser racional, aparezca a los ojos del otro.

Según Schiller el hombre moderno adolece de un exceso de racionalidad (2004, p. 608-9), lo cual le impide apreciar positivamente la multiplicidad no sólo de la naturaleza sino también del género humano. Así, el hombre moderno no se permite ser sorprendido por lo absolutamente otro. Es la impaciencia por conocer, esto es, por dominar lo exterior, aquello que lo cierra al encuentro con el otro en su otredad. Por el contrario, el reconocimiento estético, por el que aboga Schiller, implica paciencia, tranquilidad, cierta ingenuidad y fortaleza para no dejarse condicionar por los propios prejuicios sobre el otro (2004, p. 609).

En la vigésima de sus Cartas sobre la educación estética del hombre Schiller define cuatro tipos de relaciones intersubjetivas: sensible, lógica, moral y estética (2004, p. 634 n.). En la intersubjetividad sensible reconocemos del otro sólo su cualidad física por medio de lo sensible en nosotros. La búsqueda del otro es meramente búsqueda de placer. En la intersubjetividad lógica sólo reconocemos del otro aquello que le habla a nuestro entendimiento haciendo abstracción incluso del otro en cuanto sujeto del mensaje y concentrándonos sólo en el contenido del mismo. En la intersubjetividad moral se da el encuentro entre meras voluntades racionales bajo el imperio de la ley moral (kantiana). Por último, en la intersubjetividad estética experimentamos al otro dejando en suspenso la validez del imperativo categórico (kantiano) y de nuestros juicios particulares, tanto teóricos como empíricos, permitiendo así que lo que nos llegue del otro sea no sólo su mera apariencia, sino también la totalidad de su ser sin que haya mediado filtro alguno (sensible, lógico o moral).

La tolerancia recíproca entre ciudadanos de acuerdo a lo que dicta el derecho o la moralidad racional de la Ilustración no hace justicia, sostiene Schiller, 
a la naturaleza humana. Pues el sujeto del derecho y la moral es, según él, el hombre en cuanto Yo, en cuanto mero ser racional, despojado de lo que Ortega y Gasset ha llamado las circunstancias de cada existencia individual. El proyecto de una educación estética del hombre tiende a que el hombre aprenda a unir sentimientos y carácter, a tener los sentidos abiertos y el entendimiento despierto para así poder abrirse a la experiencia del otro en su otredad. De este modo la educación estética se presenta como un antídoto contra el totalitarismo de la razón ilustrada cuando pretende regir la vida de los hombres desde un punto de vista que es, según Schiller, deshumanizante. Schiller cuestiona la moral kantiana y de la Ilustración en general al preguntar:

¿Cómo podemos ser [...] ecuánimes, bondadosos y humanos los unos con los otros, si nos falta la capacidad de acoger en nosotros de modo fiel y verdadero la naturaleza que no es extraña, de apropiarnos de situaciones ajenas, de hacer nuestros los sentimientos de los otros? (SCHILLER, 2004, p. $610 \mathrm{n}$.)

Schiller sostiene que su propuesta de reconocimiento del otro en cuanto lo absolutamente otro sirve para desarrollar una verdadera tolerancia que ponga fin a la filantropía hipócrita de su tiempo, consistente en juzgar rigurosamente al otro de acuerdo a un ideal de perfección incompatible con las limitaciones humanas y que uno no está dispuesto a cumplir. Este falso reconocimiento y tolerancia hipócrita no busca, según Schiller, ayudar al otro, sino juzgarlo (2004, 611 n.).

El punto de partida de la propuesta schilleriana de pensar el reconocimiento desde la diferencia es la idea de que el hombre es un compuesto indivisible de razón y naturaleza, de espíritu y contingencia histórica. La nacionalidad, el bagaje cultural y la religión de uno no son pues algo accidental sino constitutivo de la identidad individual. Una praxis de reconocimiento debe entonces buscar la afirmación de lo que hace del otro otro, en lugar de buscar lo mismo en el otro para así neutralizar o relativizar aquello que es ajeno a la naturaleza racional de todo hombre. 


\subsection{Schelling: reconocimiento a partir y por medio del disenso ${ }^{8}$}

Al igual que la propuesta de Schiller, el concepto schellingiano de reconocimiento en su Nueva deducción del derecho natural constituye una excepción no sólo a la regla del pensamiento de la Ilustración sino a la del pensamiento filosófico político moderno en general. ${ }^{9} \mathrm{La}$ originalidad reside en haber visto que la praxis de reconocimiento recíproco que nos constituye como seres morales y sujetos de derecho no consiste en un acuerdo entre las partes basado en haber comprendido y aceptado qué es aquello que todos somos más allá de nuestras diferencias circunstanciales. Por el contrario, el reconocimiento verdadero surge de un choque entre voluntades. Sólo reconozco que en el otro también hay humanidad cuando el otro pone un freno a mi voluntad, a mis deseos, cuando el otro pone en cuestión mi manera de ver las cosas.

Que un ser similar a mí en su apariencia externa pueda ser modificado por mi voluntad o intención no es prueba suficiente de que este ser sea un ser humano. Pues podría ser un animal adiestrado. Esto se confirma con la observación de que aquellos cuyas demandas nunca sufren resistencia de otras voluntades humanas, acaban por perder el respeto por la dócil especie humana y, finalmente, también por la dignidad humana misma. Sólo cuando me dirijo a la voluntad de otro ser humano y éste rechaza mis demandas con un categórico "iNo quiero!" o cuando éste está dispuesto a ceder su libertad por el precio de la mía, sólo entonces reconozco que detrás de ese rostro hay humanidad y en su pecho, libertad (SCHELLING, 1980, p. 223)

En la resistencia contra una voluntad particular se manifiesta, según Schelling, la racionalidad y la libertad humanas. El reconocimiento entonces no sólo se inicia necesariamente con una experiencia de desacuerdo entre las partes, sino que este momento de tensión, de disenso, constituye la experiencia misma del reconocimiento. Los individuos pues se constituyen y son reconocidos como sujetos racionales, lo que aquí significa, dignos de ser respetados en su integridad, mediante el resistirse a los deseos y mandatos del otro. Schelling no habría

\footnotetext{
${ }^{8}$ Cabe mencionar que el pensamiento de Schelling ya ha sido tratado en relación a otras temáticas sobre el estudio de la religión, tales como la cuestión de la revelación y de la tensión entre libertad individual y absoluto, por Bruno Forte (véase p.ej. 2013, p. 92-95).

${ }_{9}^{9}$ Para una exposición más detallada de este concepto véase ACOSTA, 2014b.
} 
aceptado la amistad de Saladino, pues para él la verdadera amistad supone que ambos hayan podido mantenerse firmes en sus convicciones originarias.

Puede suponerse que en el planteo de Schelling la experiencia del disenso es un momento que luego es superado en su deducción del derecho natural, pero en realidad es todo lo contrario. En primer lugar, el escenario del disenso viene deducido en la obra de Schelling a partir de una idea de razón universal que en cuanto absoluta es indeterminada. El conflicto del que surge el reconocimiento viene entonces exigido por la naturaleza indeterminada misma de la razón universal. Si esta razón universal tuviera un contenido concreto, no habría argumento de por qué defender el disenso, ya que habría un criterio para distinguir verdad de falsedad. La indeterminación de la razón universal es lo que posibilita la afirmación de los pareceres particulares y, de este modo, también el imperativo de no reducir las particularidades a una supuesta verdad moral universal. En segundo lugar, Schelling entiende que ese foco de disenso originario debe mantenerse, pues sobre él están basados no sólo la moralidad, sino también el derecho y la eticidad. La dinámica de las relaciones humanas se alimenta de este disenso originario, sin él no hay progreso, sin progreso no hay historia de la humanidad (SCHELLING, 1980, p. 226-232).

\section{A modo de conclusión}

Propusimos en un principio desarrollar una mirada del diálogo interreligioso a la luz del legado figurativo y conceptual de tres pensadores de la Ilustración en sentido amplio: Lessing, Schiller y Schelling. La idea, dijimos, consistía en utilizar este legado como un espejo en el podamos ver sobre todo los desafíos que debe enfrentar el proyecto del dialogo inter-religioso.

La versión de Lessing de la parábola de los tres anillos permite ver lo pernicioso de una praxis de reconocimiento y tolerancia guiada por una lógica de la identidad donde el mecanismo de inclusión por medio de exclusión ocupa un lugar 
preponderante. El modo en que Lessing describe la situación misma del diálogo nos permite además advertir que muchas veces el diálogo no es algo buscado por las partes, sino que las partes se ven obligadas a entrar en diálogo. Este punto nos parece de suma importancia para no caer en argumentos voluntaristas. Creemos que se debe, por el contrario, intentar demostrar que el diálogo inter-religioso no es una opción, ni una mera invitación, sino una necesidad que nace de la conflictividad actual en nuestras sociedades multi-religiosas. Por otra parte, Lessing puede enseñarnos a ver que en todo diálogo siempre hay una asimetría entre las partes. En el caso del diálogo inter-religioso es de verse que las religiones llamadas a dialogar no poseen el mismo poder dentro de un mismo país, sea por tradición, por presencia en la cultura contemporánea y en la política o por cantidad de creyentes. Para neutralizar esta asimetría originaria creemos que las autoridades políticas nacionales e internacionales podrían prestar un gran servicio. De allí que también resulte interesante tomar en cuenta el motivo del juez en la parábola de Lessing al que acuden los hermanos. Dicho con otras palabras, la cuestión interreligiosa debe ser vista no sólo como un problema del creyente en un mundo polireligioso, sino además como una cuestión política, como una responsabilidad y deber de las autoridades políticas.

Que el Estado no debe neutralizar las diferencias, siguiendo el modelo secularizador de la Ilustración, ya lo hemos indicado al inicio de nuestro trabajo. Tomando el aporte de Schelling podemos sugerir que la praxis del Estado debe principalmente regular las asimetrías de poder entre las partes involucradas en el diálogo de modo que cada parte puerta afirmar su identidad o, dicho con Schelling, resistir el discurso del otro que busca hegemonizarse.

Lo "inter" de lo inter-religioso se muestra pues no como una situación dada sino como tarea: lograr que cada credo pueda expresar su identidad de modo que ese "inter" sea posible. Para esto puede prestar su servicio el programa de una educación estética del hombre con su idea de un reconocimiento estético. Siguiendo a Schiller creemos que la educación inter-religiosa debe enseñar a ver al 
otro de un modo plural, abierto a las diferencias, debe enseñar a ser paciente e incluso, como sostiene Schiller, ingenuo. Pero esta praxis educativa no debe llevarse a cabo porque las diferencias deben ser toleradas sin más, sino porque estas diferencias son tan constitutivas del otro como lo son de mí mismo. Detrás de lo accidental de cada existencia individual no hay, como sugiere Schiller, nada, el ser humano sin más es una abstracción cuya aplicación política o ética para juzgar a los otros puede resultar opresiva.

El punto central de lo inter-religioso, según nuestro estudio, consiste en la ausencia de una verdad última: debemos aprender a reconocer que el anillo se ha perdido para siempre, que, si existe la verdad, la misma, siguiendo a Schiller, es contraproducente para un diálogo inter-religioso, o, siguiendo a Schelling, es indeterminada, de allí que toda religión sea verdadera, no por ser algo accidental, sino porque toda verdad es necesariamente particular.

No creemos, pues, que como sostiene Hutswit (2014), el desafío consista en buscar argumentos teóricos más fuertes para construir una nueva verdad para distinguir entre mejor y peor, sino en una praxis de promoción y protección de las diferencias entendidas como constitutivas de todo grupo humano. Sólo así lo que en gran medida es un proyecto o una realización sólo en círculos específicos, puede llegar a ser un principio tan obvio como incontestable para empezar a ver la pluralidad de religiones en las sociedades actuales ya no como un problema, sino como la afirmación de la naturaleza y la dignidad humanas.

\section{REFERENCIAS}

ACOSTA, Emiliano. Power, Public Opinion, Right of Rebellion and Revolution in the Tractatus Theologico-politicus. Toward a Deconstruction of the Radicalness of Spinoza's Political Thought. In: TORME, T.; LANDENNE, Q. L'actualité du Tractatus de Spinoza et la question théologico-politique. Séries: Philosophie politique: généalogies et actualités. Brussel: Presses Universitaires de Bruxelles, 2014a, p. 247-265. 
ACOSTA, Emiliano. Recognition and Dissent. Schelling's Conception of Recognition and its Contribution to Contemporary Political Philosophy. In: Cobben, P.; Krijnen, Ch.

Recognition - German Idealism as Ongoing Challenge. Series Critical Studies in German Idealism vol. 10. Leiden: Brill, 2014b, p. 143-164.

ACOSTA, Emiliano. Schiller and the Recognition of the Other in his or her Otherness: the challenge of thinking Intersubjectivity according to a logic of the difference.

Pensamiento, Espanha, v. 68, n. 256, 2012, p. 225-247.

BALIBAR, Étienne. Dissonances dans la laïcité. In: Mouvements, Paris: v. 3, n. 33-34, 2004, p. 148-161. Disponível em: <http://www.cairn.info/revue-mouvements-2004-3page-148.htm> Acesso em: 20 nov. 2016. DOI : 10.3917/mouv.033.0148.

BEITZ, Charles R. Cosmopolitanism and Global Justice. The journal of ethics, v. 9, n. 1/2, 2005, p. 11-27.

BOCCACCIO, Giovanni. Decamerón. Madrid: Planeta, 1982.

DESCOULEURS, Bernard. La place problématique de la religion en régime de laïcité. La pensée, Paris, n. 342, 2005, p. 107-118.

FORTE, B. Die Christologie und die Wahrheitsfrage. In: AGUSTIN, Georg et al. Mein Herr und mein Gott: Christus bekennen und verkünden. Freiburg: Herder, 2013, p. 86100.

FRANCISCO. Mensaje del santo padre francisco con motivo del 50 aniversario de fundación del organismo para el diálogo con las religiones. Disponível em: <http://w2.vatican.va/content/francesco/es/messages/pontmessages/2014/documents/papa-francesco_20140519_messaggio-50-dialogointerreligioso.html>. Acceso em: 15 nov. 2016.

HABERMAS, Jürgen. Glauben und Wissen: Rede zum Friedenspreis des Deutschen Buchhandels 2001. Frankfurt: Suhrkamp, 2001.

HACINEBIOGLU, I.L. The search for a common epistemological ground within the InterReligious framework: a concept-centered approach. In: ENGEBRETSON, Kath et al. International Handbook of Inter-religious Education. Dordrecht/ Heidelberg/ London/ New York: Springer, 2010, p. 73-83.

HOUTMAN, Dick; AUPERS, Stef. The Spiritual Turn and the Decline of Tradition: The Spread of Post-Christian Spirituality in 14 Western Countries, 1981-2000. Journal for the Scientific Study of Religion, Oxford: v. 46, n. 3, 2007, p. 305-320.

HUSTWIT, J. R. Interreligious Hermeneutics and the Pursuit of Faith. Lanham: Lexington Books, 2014.

ISRAEL, Jonathan I. Enlightenment Contested: Philosophy, Modernity, and the Emancipation of Man 1670-1752. Oxford: Oxford University Press, 2006. 
LESSING, Gotthold E. Nathan der Weise. Ein dramatisches Gedicht in fünf Aufzügen. Berlin: Christian Friedrich Voß und Söhn, 1779.

LIGHT, Aimee U. Post Pluralism Through the Lens of Post Modernity. The Journal of Inter-Religious Dialogue, Boston: v.1, 2009, p. 67-71.

ORTEZA y MIRANDA, Evelina. Religious Pluralism and the Paradigm. In:

ENGEBRETSON, Kath et al. International Handbook of Inter-Religious

Education. Dordrecht/ Heidelberg/ London/ New York: Springer, 2010, p. 5-24.

PAIVA, Márcio A. Da veritas à caritas: a religião depois da religião. Horizonte, Belo Horizonte, v. 13, n. 37 2015, p. 406-427.

SCHELLING, Friedrich W. J. The unconditional in Human Knowledge. Four Early Essays (1794-1796). Lewisburg, PA: Bucknell University Press, 1980.

SCHILLER, Friedrich. Über die ästhetische Erziehung des Menschen in einer Reihe von Briefen. In: SCHILLER, F. Sämtliche Werke in 5 Bänden. München: Deutscher Taschenbuch Verlag, 2004, tomo V, p. 570-699.

STROUSE, Susan. The Intrafaith Conversation: How Do Christians Talk Among Ourselves About Interfaith Matters? USA: Wilgefortis: 2016.

VANHOOZER, Kevin J. Theology and the Condition of Postmodernity: a Report on Knowledge (of God). The Cambridge Companion to Postmodern Theology, Cambridge: Cambridge University Press, 2003, p. 3-25.

VATTIMO, Gianni. Credere di credere. Milano: Garzanti, 1997.

ZAIDI, Ali H. A critical misunderstanding - Islam and dialogue in the human sciences. International Sociology, Los Angeles/ London/ New Delhi/ Singaporev: 22, n. 4, 2007, p. 411-434. 